\title{
Los inmigrantes extranjeros en el espacio social madrileño ${ }^{1}$
}

\author{
Vicente Rodriguez Rodriguez * \\ M. PIlar González Yancl ** \\ M. ${ }^{a}$ José Aguilera ArILla ***
}

\section{INTRODUCCIÓN}

España se ha convertido en los últimos años en un pais de inmigración frente a la situación tradicional, en la que predominaba su papel de emisor. Madrid representa, en el conjunto del Estado, uno de los principales focos de atracción, al que llegan inmigrantes de todos los continentes, con muy variadas caracteristicas demográficas, asi como con diversas motivaciones económicas y políticas.

En este trabajo se analiza la inmigración de extranjeros a la ciudad atendiendo a su procedencia y localización, para tratar de verificar la hipótesis de que existe una relación entre las caracteristicas socioeconómicas de aquéllos y las áreas sociales de Madrid en las que se ubican. Para ello se ha dividido el estudio en tres partes: la primera, describe los rasgos generales de los inmigrantes (demográficos, culturales, profesionales, sociales, etc.); la segunda, partiendo de trabajos de varios autores, presenta las diversas áreas sociales de la ciudad. En la tercera se ponen en relación los grupos humanos y los espacios urbanos para, por medio

1 Este articulo corresponde a la traducción de la comunicación presentada al Symposium "The Urban Population at the micro-scale", organizado por la IGV Commission on Population Geography que se celebró en Varsovia en septiembre de 1991. Para su realización se ha contado con una ayuda de investigación del Instituto Español de Emigración para el «Estudio de la ocupación, caracteristicas, localización y alojamiento de los inmigrantes extranjeros en Madrid y Corona Metropolitana".

* Centro de Estudios Sociales. CSIC.

** Departamento de Geografía. UNED.

*** Departamento de Geografia. UNED. 
del análisis factorial, constatar la hipótesis inicial y establecer las principales categorias de inmigrantes.

\section{CARACTERISTIICAS GENERALES}

A partir de los últimos datos oficiales disponibles (Padrón Municipal de Habitantes de 1986) en Madrid habia 32.120 extranjeros, lo que representaba el $1 \%$ del total de la población. Un elevado porcentaje de ellos $(57 \%)$ llegó al municipio entre 1976 y 1986 y muy especialmente en los años posteriores al ochenta, en un proceso de incremento especialmente acusado a partir de 1984. Dicho grupo, compuesto por 18.278 personas es el que se va a considerar en este análisis, ya que es el que mejor representa las características de la reciente inmigración a Madrid y, en cierto modo, extrapolando los resultados, las de otros espacios españoles semejantes. Es, además, el grupo más estable y mejor caracterizado, por estar empadronado, y es el más heterogéneo. Obviamente comprende sólo a los que residen «legalmente» en el pais, quedando fuera del estudio el cada día más numeroso grupo de inmigrantes clandestinos, formado en su mayoría por extranjeros procedentes del Tercer Mundo, en especial de África.

Del grupo citado, aproximadamente la mitad procede de América $(46,8 \%)$, con predominio casi absoluto de latinoamericanos; un $30 \%$ proviene de Europa y el resto se distribuye entre los que llegan de Asia y África, con cifras muy inferiores (14,7 y $8,5 \%$ respectivamente). Por paises, entre los que representan valores más elevados, hay una clara relación de proximidad física (Portugal, Marruecos, Francia, Italia, Reino Unido y Alemania), e histórico-cultural (Argentina, Cuba, Chile, Colombia y Filipinas). Además, destaca el caso de Estados Unidos por razones esencialmente económicas y políticas (presencia de bases militares y empresas multinacionales).

Globalmente considerados, y aunque se distribuyen por todos los distritos de Madrid, se observa un predominio de extranjeros en el Norte y centro de la ciudad, mientras que hay pocos instalados en la periferia. (Fig. 3).

Desde una perspectiva general se puede definir al conjunto de extranjeros residentes en Madrid por sus rasgos más destacados: respecto a su estructura demográfica componen un grupo en el que se da un claro predominio de adultos (el $78,5 \%$ tiene entre 15 y 64 años) siendo especialmente numerosos los que están entre los 20 y 44 años. Es también 
destacable el alto porcentaje de mujeres frente a varones (con una sex ratio del 80,7 ) y de solteros, que alcanzan casi el $26 \%$ de los mayores de 20 años.

En el análisis de estas características demográficas, así como en las restantes que veremos a continuación (actividad económica, nivel cultural, etc.) si consideramos el origen (pais de procedencia) y el destino (distrito o barrio de la ciudad en que se instalan) podemos apreciar una notable diversidad y existencia de contrastes. Si la pirámide general mostraba, como hemos comentado, un predominio de adultos y de mujeres, las pirámides parciales presentan algunas diferencias: los africanos y sudamericanos tienen mayor equilibrio por sexos, siendo junto a los asiáticos, los que tienen tasas de masculinidad más elevadas. Los norteamericanos, europeos, y algo menos los centroamericanos, tienen un acusado predominio femenino $y$, consiguientemente, tasas de masculinidad muy bajas. En todas las nacionalidades el grupo de adultos (especialmente entre 20 y 44 años) es muy predominante, si bien entre los asiáticos es destacable el bajísimo número de jóvenes y ancianos. Por distritos (Fig. 1) Retiro, Moncloa y Villaverde son los que presentan mayor predominio de mujeres, siendo sólo San Blas y Puente de Vallecas los que tienen más varones. En todos los distritos las pirámides resultan muy desequilibradas, tanto por sexo como por edad, como puede observarse en algunos ejemplos seleccionados. (Fig. 2).

El indice de solteria tambièn presenta contrastes. Los mayores volúmenes de solteros se dan entre africanos y sudamericanos. A su vez por distritos hay mayor número en algunos de los céntricos (Centro, Moncloa, Salamanca) y en dos periféricos (Vicálvaro y Carabanchel). Los casados predominan en los periféricos del Norte y Este (Barajas, Villa de Vallecas, Hortaleza, Ciudad Lineal y Fuencarral).

El nivel cultural resulta muy variado. Es de destacar el elevado porcentaje de titulados superiores $(18,1 \%)$ y el de «sin estudios" $(27,3 \%)$, aunque en este caso la realidad queda encubierta por el número de menores de 15 años que se engloban en los datos.

Por procedencia son los europeos los que tienen mayor porcentaje de titulados superiores, seguidos por los americanos, entre los cuales los de Estados Unidos alcanzan la mayor proporción considerando su número. Por el contrario, en el grupo de "sin estudios" sobresalen los africanos. En el interior de la ciudad los distritos con zonas residenciales de más calidad acogen a la mayor proporción de titulados superiores; Chamartín presenta el máximo, con el $23,2 \%$, seguido de Salamanca, Chamberí, Retiro, Moncloa, Fuencarral, Barajas y Moratalaz. Por el contrario, en los distritos de menor nivel socioeconómico predominan los que se declaran 
"sin estudios" (Puente de Vallecas, Usera, Vicálvaro, Villaverde y Carabanchel). En cuanto a la actividad económica del conjunto de extranjeros, casi el $42 \%$ son población activa, estando ligeramente por encima de la media nacional. De ellos un $7 \%$ son parados o están buscando su primer empleo. Dicha población activa se ocupa preferentemente en el sector terciario, al igual que ocurre con las empresas en las que trabajan. El $80 \%$ de éstas se enmarcan en el citado grupo, con neto predominio de las de servicios $(55,5 \%)$ y comercio-hosteleria $(23 \%)$. Apenas hay representadas empresas dedicadas al sector primario, siendo sólo un $17 \%$ las que corresponden a construcción e industrias. Muy similar es la distribución de los extranjeros por su ocupación. Hay predominio absoluto del sector terciario, en el que podemos destacar: administrativos, servicio domésti$\mathrm{co}$, profesores, directores y gerentes de empresa, propietarios y empleados de comercio, cocineros y camareros y profesionales del espectáculo, en el orden en que se han enumerado.

Estos rasgos económicos relacionados con la procedencia y localización en la ciudad vuelven a incidir en la existencia de una distinción clara. Por un lado, los mayores porcentajes de población trabajadora se dan entre europeos y asiáticos y se localizan en los distritos que acogen a mayor número de inmigrantes que son, además, los que tienen mayor dinamismo económico y social (Salamanca, Chamartín y Chamberi). Por otro, los africanos y latinoamericanos tienen los mayores porcentajes de parados y de quienes buscan su primer empleo, localizándose a su vez en los distritos de menor nivel del Sur y Sudeste (Arganzuela, Carabanchel, Villaverde, Usera, Puente de Vallecas, etc.).

El volumen de jubilados, tan sólo un $3 \%$, es, en cambio, significativo. En su mayoria corresponde a europeos y americanos del Norte y del Sur, que se localizan en los barrios de mayor status (Retiro, Salamanca, Chamberi, Fuencarral y Chamartín).

Dentro del terciario, que ocupa a la mayoria de la población extranjera, sin entrar en demasiados detalles, se pueden citar algunos ejemplos significativos. El grupo de mayor rango (finanzas, administración y gestión de empresas) son europeos, norteamericanos y americanos del Sur y se ubican en los distritos de más alto nivel (Salamanca, Chamartin, Chamberi, Fuencarral y Moncloa). Los asiáticos, seguidos a distancia por los africanos, proporcionan mano de obra a comercio y hostelería, localizados sobre todo en Centro, Tetuán y Chamartin. El pequeño porcentaje de los que trabajan en industria es, en su mayor parte, de europeos y americanos y se localiza en distritos como Fuencarral y Chamartin, al Norte de la ciudad, en áreas de tejido industrial, donde abundan las empresas multinacionales. 
Por último, respecto a la profesión y situación profesional se repite el esquema anterior. Un $30,2 \%$ son profesionales, técnicos y similares. Se dedican a actividades que requieren una elevada preparación y en su mayoria se trata de los procedentes de Europa y América (más del $80 \%$ ), localizándose en los distritos de mayor nivel (Centro, Retiro, Salamanca, Chamartín y Ciudad Lineal, con un $52 \%$ ). Los empleados en hosteleria y servicio doméstico representan el $20 \%$ y los administrativos el $19 \%$. En este caso el predominio es para los asiáticos, africanos y centroamericanos con un $55 \%$. Resulta un grupo más heterogéneo que el anterior, con representación de todos los paises y que se distribuye también de forma aleatoria.

La situación profesional predominante es la de asalariados fijos, con un $56 \%$ del total, al que se añade un $14 \%$ de asalariados eventuales. Una diferencia notable en este grupo se da entre los europeos y norteamericanos, que llegan con un contrato de trabajo, y el resto, que lo consigue una vez en el pais. También es de destacar la considerable presencia de empresarios, de los que cerca de un $13 \%$ no emplean personal (un $45 \%$ de sudamericanos y un $21 \%$ de europeos) y un porcentaje menor que si tienen personal empleado ( $31 \%$ europeos, $25 \%$ asiáticos y $29 \%$ sudamericanos). Este grupo se localiza, en el primer caso en los distritos de Centro, Chamartín y Ciudad Lineal y en el segundo en Chamartin y Fuencarral ${ }^{2}$.

En conclusión, el grupo de extranjeros de reciente inmigración residentes en Madrid, es amplio y heterogéneo, con un elevado volumen de jóvenes y predominio de mujeres. Presenta un fuerte contraste entre dos grandes bloques: los procedentes del mundo más desarrollado, que tienen el mayor nivel cultural y realizan las actividades de más alto rango y cualificación, y los procedentes del Tercer Mundo, que se ocupan de trabajos del sector terciario, de menor categoria. El contraste se da en todos los demás rasgos y vuelve a aparecer en su distribución en la ciudad, de modo que los distritos de más alto nivel socieconómico albergan a mayor número de los inmigrantes del primer bloque, mientras que los del segundo se reparten predominantemente por los distritos menos favorecidos. (Figs. 2 y 3 ).

Se ha de hacer una importante matización: tanto en lo referente a actividad, personal o de la empresa, como a profesión y situación profesional, es muy elevado el número de los que figuran "sin especificar". En el estudio se han considerado las respuestas precisas y se han referido a cien, sirviendo asi como una muestra muy significativa. 

1. Centro
2. Arganzuela
3. Retiro
4. Salamanca
5. Chamartin
6. Tetuán
7. Chamberi
8. Fuencarral
9. Moncloa
10. Latina
11. Carabanchel
12. Usera
13. Puente de Vallecas
14. Moratalaz

15. Ciudad Lineal
16. Hortaleza
17. Villaverde
18. Villa de Vallecas
19. Vicálvaro
20. San Blas.
21. Barajas

15. Ciudad Lineal

18. Villa de Vallecas

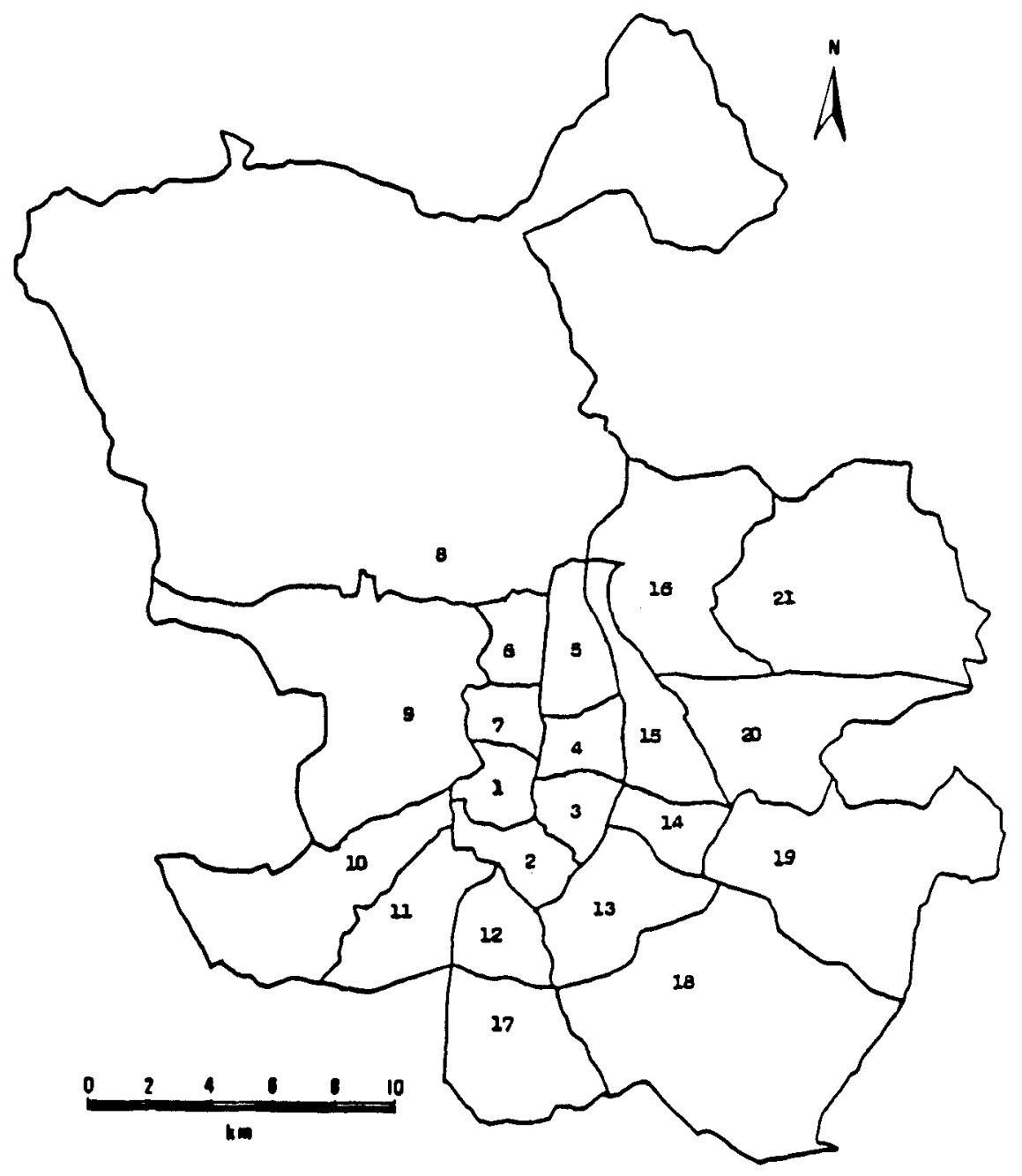

Fig. 1. Distritos de Madrid 


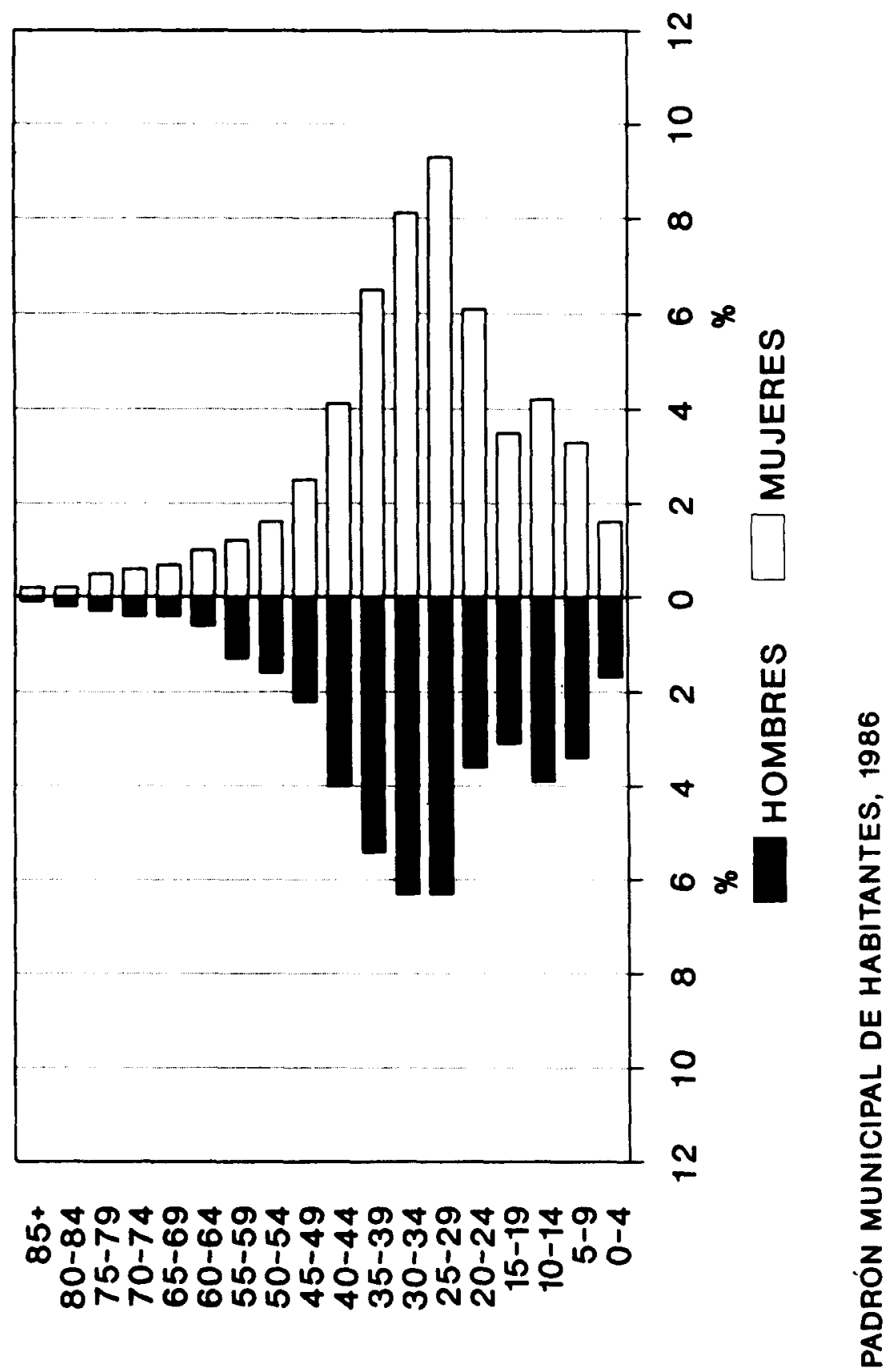

Fig. 2. Inmigrantes extranjeros en Madrid (1976-1986) 

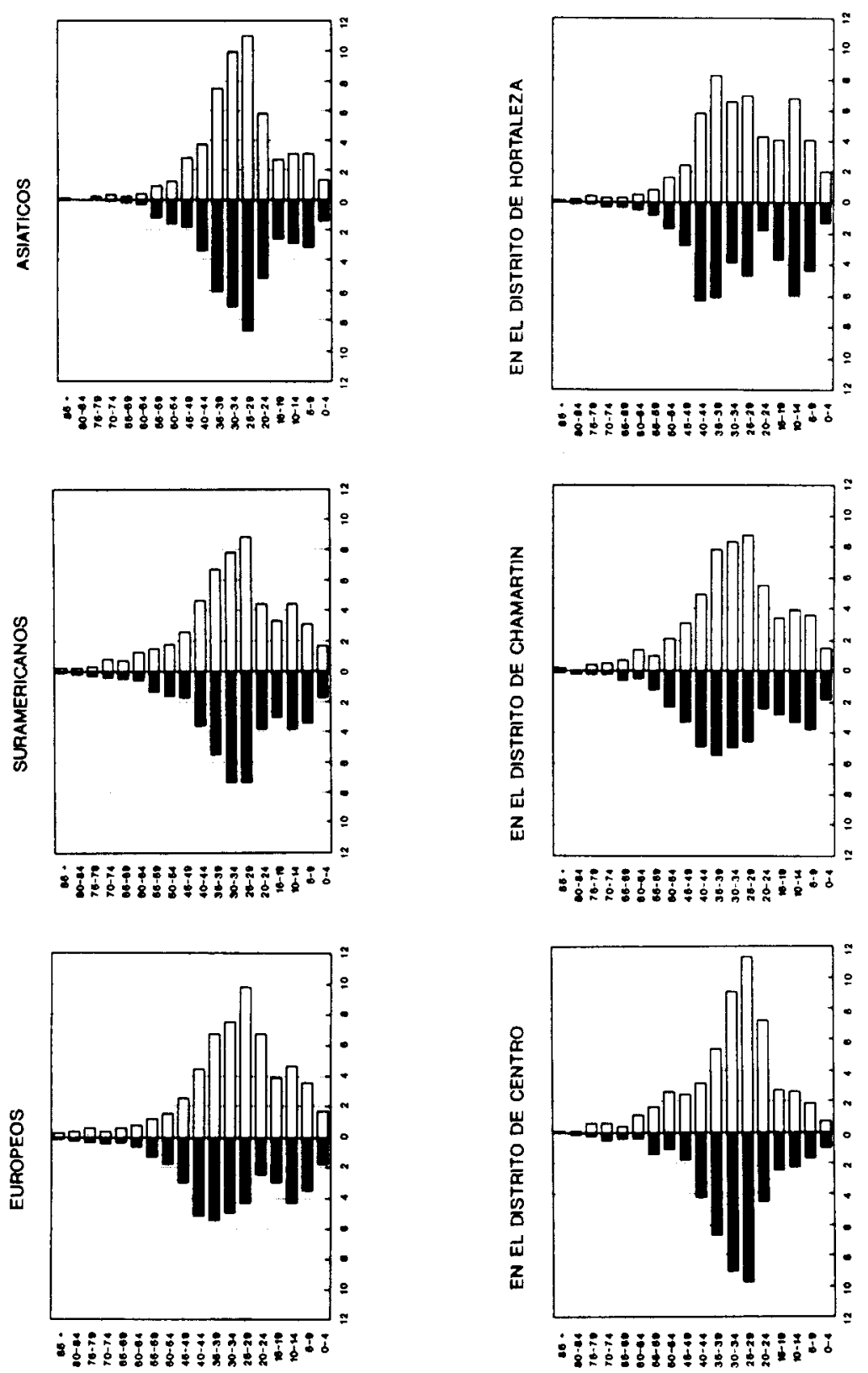

Fig. 2. Inmigrantes extranjeros en Madrid (1976-1986) 

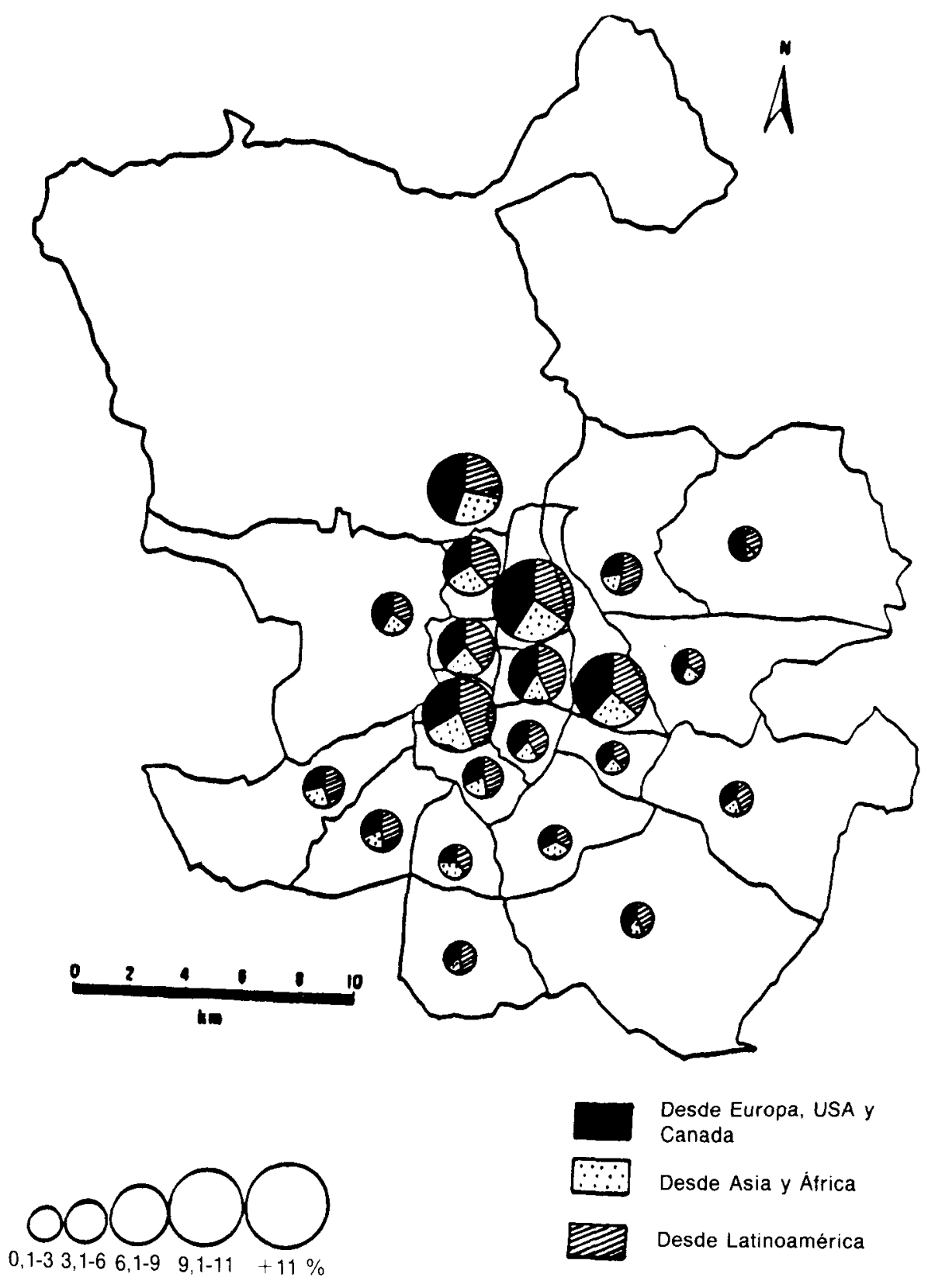

Fig. 3. Porcentaje de inmigrantes extranjeros en Madrid por distritos (1986) 


\section{LAS ÁREAS SOCIALES DE MADRID}

El análisis del espacio social en Madrid ha sido, desde finales de los años sesenta, un tema de gran interés para geógrafos y sociólogos. Prueba de ello es el número de publicaciones que lo tienen por objetivo (LoRATAMAYO 1990) ${ }^{3}$.

No se trata aquí de hacer una valoración de estos trabajos, ni de su metodología para establecer la diferenciación socioespacial de Madrid, sino de exponer, de forma gráfica y resumida, las caracteristicas sociales, económicas y demográficas del espacio urbano madrileño, para así comprender mejor la localización y rasgos estructurales de los inmigrantes extranjeros en ese espacio, en la última década.

Castells (1981) utiliza el análisis factorial para establecer las diferencias sociales y funcionales en Madrid, a partir del Padrón Municipal de 1975, actualizado en 1977, y los datos de la Comisión de Planeamiento del Área Metropolitana de Madrid (COPLACO). De la primera fuente extrae 68 variables sociodemográficas para los 119 barrios y de la segunda 50 variables de carácter urbano, para 62 zonas. Este trabajo no ha sido utilizado porque sus resultados son complejos y de difícil simplificación.

Campo (1983), partiendo de 14 variables sociodemográficas obtenidas también del padrón, y sirviéndose de análisis cluster, diferencia siete subáreas homogéneas, formadas por 86 barrios ( $72 \%$ del total) y una serie de áreas de segregación, más pequeñas y heterogéneas. En una segunda fase, por medio de análisis de correspondencias, identifica áreas sociales en función del status económico alto y bajo, del carácter central y periférico del barrio y de la juventud o envejecimiento de su población. Por motivos semejantes al caso anterior tampoco ha sido tomado como base para nuestro trabajo.

Jiménez (1984) extrae 16 variables sociodemográficas, de la misma fuente que en los anteriores estudios, para los 119 barrios. Mediante análisis factorial de componentes principales, resume la información en dos factores que explican más del $80 \%$ de la varianza: un factor de nivel socioeconómico y otro, de carácter demográfico, denominado «urbanización». A partir de ellos delimita seis áreas sociales en Madrid.

Posteriormente esta autora, en 1986, realizó un nuevo análisis con 14 variables, eliminando tres de las anteriores y añadiendo una nueva. Los

\footnotetext{
${ }^{3}$ Esta autora hace una revisión de los estudios sobre áreas sociales, tanto generales (FOeSSA) como especificos, (CAstells 1981; Campo 1983 y Jiménez 1984 y 1986).
} 
factores definidos son «rango social», «envejecimiento-juventud» y «familismo", que explican el $87 \%$ de la varianza. El primer factor incluye con carga positiva la población que tiene titulación superior y bachillerato, que son directivos y técnicos de empresa, y que emplea a trabajadores del servicio doméstico, y con carga negativa, los trabajadores manuales y con nivel académico elemental. El factor envejecimiento-juventud incluye la población joven (hasta 20 años), los estudiantes y el índice de fecundidad, con valores positivos, y viviendas habitadas por una o dos personas mayores de 65 años, con cargas negativas. El último factor lo definen variables como personas casadas, indice de fecundidad, amas de casa, con signo positivo, y trabajadores de servicio doméstico, población anciana y titulados superiores, con valores negativos y escasa significación.

Los tipos de áreas sociales, obtenidas por medio de un análisis cluster, son las siguientes:

\begin{tabular}{ccc}
\hline TIPO & ENVEJECIMIENTO & RANGo SOCIAL \\
\hline 1 & Muy alto & Bajo \\
2 & Alto & Alto \\
3 & Alto & Bajo \\
4 & Medio & Medio \\
5 & Bajo & Bajo \\
6 & Medio-alto & Medio-alto \\
7 & Alto & Muy alto \\
\hline
\end{tabular}

Conforme a esta tipologia, Jiménez (1986) afirma "la ciudad de Madrid se adapta bastante bien al modelo de Murdie, pues el factor rango social se estructura espacialmente en forma sectorial y el factor envejecimiento demográfico según el modelo concéntrico".

El factor rango social resulta el más significativo para establecer grandes áreas sociales que resuman los siete tipos creados anteriormente. Agrupando los tipos 1, 3 y 5 por un lado, el 2 y el 7 por otro, y finalmente el 4 y el 6 , se han reducido a tres las principales zonas a considerar en Madrid, representadas en el mapa de la figura 4. Con ello se pretende establecer un marco de referencia para comprender la distribución de los inmigrantes extranjeros según su procedencia y características en el tejido urbano de la ciudad que les acoge. 

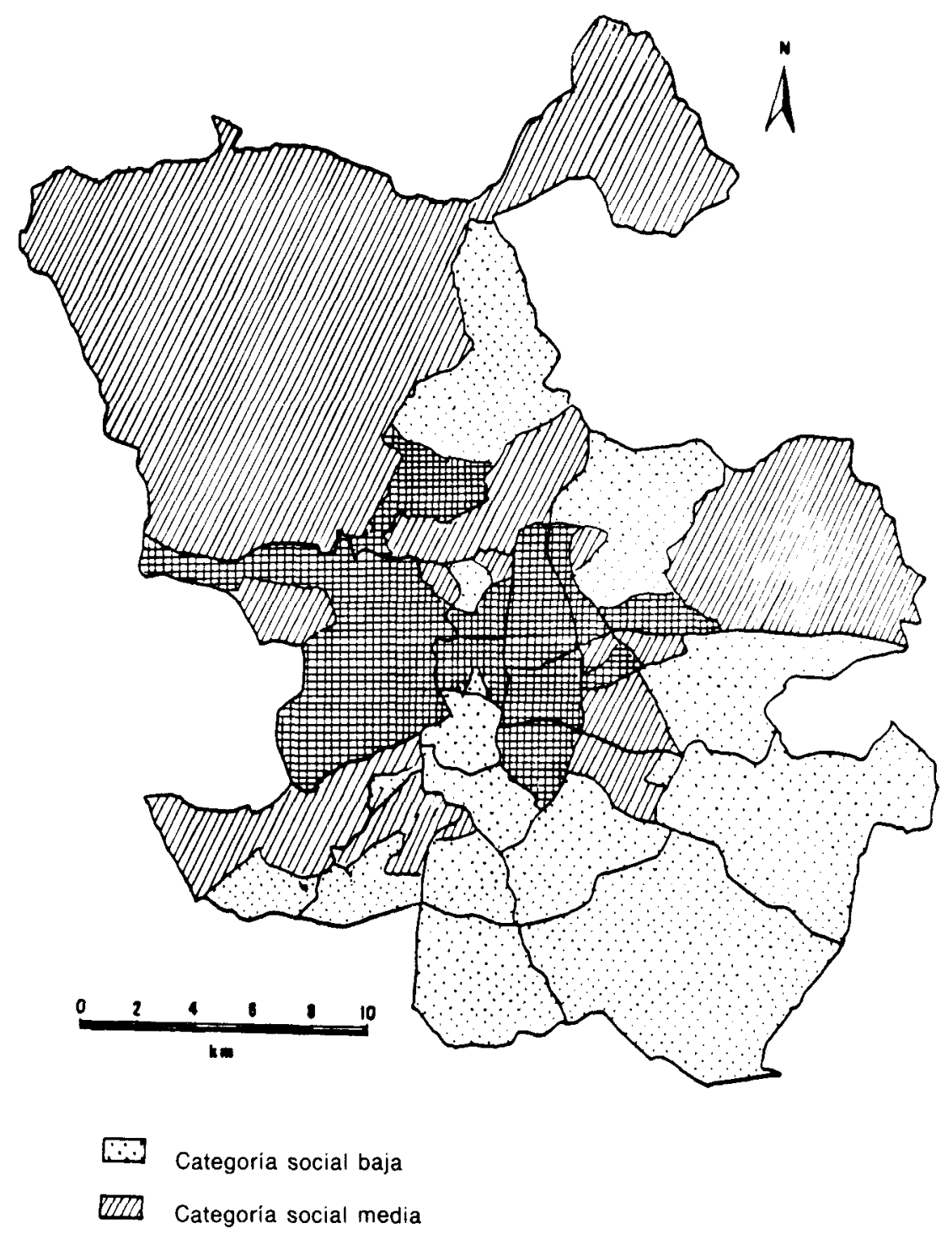

Categoria social alta

Fig. 4. Las áreas sociales en Madrid 


\section{CATEGORIAS}

De acuerdo con las características generales de los inmigrantes extranjeros y tras analizar la existencia de diferencias sociales en el espacio urbano madrileño, resulta conveniente constatar la adecuación entre los tipos de inmigrantes y su localización diferenciada en Madrid.

De forma similar a los estudios de identificación de áreas sociales, el análisis factorial permite seleccionar los parámetros más significativos de los inmigrantes extranjeros, a partir de una serie de variables extraidas del Padrón Municipal de Habitantes de 1986. Sin embargo, no es conveniente utilizar toda la información disponible, para evitar los problemas de redundancia que pueden surgir, de manera que se han seleccionado aquéllas que contribuyen a una mejor caracterización de los grupos de inmigrantes, de acuerdo con los análisis previos realizados.

Se han utilizado 13 variables después de un proceso de depuración y selección según su significado científico y estadistico:

- \% de población inmigrante joven (JOVEN).

- Tasa de dependencia de la población (jóvenes y viejos divididos entre la población adulta (DEPEND).

- Tasa de actividad (ACTIV).

- Tasa de paro sobre el total de la población activa (PARO).

- \% de jubilados sobre la población activa (RETIRO).

- \% de población empleada en empresas de comercio y hostelería (COMERC).

- \% de población empleada en instituciones financieras (FINAN).

— \% de profesionales y técnicos (PROFES).

- \% de personal de servicios administrativos (ADMINIS).

- \% de población dedicada a servicios personales y domésticos (SERVPER)

- $\%$ de asalariados fijos (ASALAR).

_ \% de población con titulación superior (diplomados y licenciados) (UNIVER).

— \% de población con estudios primarios (ESTPRIMA).

Se han extraido dos factores que explican en su conjunto el $68,5 \%$ de la varianza total, con una significación de cada variable superior a 0,6. 
Con objeto de que las variables tengan una representación más ajustada en el plano de los dos factores, se ha ejecutado la rotación Varimax.

El primer factor $(41 \%)$ está definido, con significación positiva, por variables que caracterizan a inmigrantes extranjeros con una elevada cualificación académica y profesional (UNIVER, FINAN, PROFES, ADMINIS, ASALAR), incluso aquella población retirada de su actividad económica, pero que ejerce todavía una profesión de tipo libre. En el otro lado del factor, la escasa preparación académica (ESTPRIMA) condiciona la obtención de un puesto de trabajo (PARO). Puede ser, entonces, denominado como «factor de nivel académico y profesional».

El segundo factor, con un $27,3 \%$, está definido por una población empleada en empresas comerciales y hoteleras (COMERC), con un nivel académico elemental (ESTPRIMA), siendo un grupo humano joven y dependiente. Puede ser denominado como "factor de juventud y terciario de bajo nivel".

La representación de variables, localización en distritos y procedencia de los inmigrantes (Fig. 5) permite extraer algunas relaciones interesantes.

Un primer bloque está formado por aquellos inmigrantes que tienen unos valores positivos en el primer factor (una tendencia hacia una mayor preparación académica y profesional). Dentro de ellos, los europeos tienen también una relación positiva con el segundo factor, dada la heterogeneidad de los paises de origen (Reino Unido frente a Portugal). Su localización coincide con los distritos tradicionales de alto nivel (Retiro, Chamartín, Salamanca, etc.). En cambio, los norteamericanos aparecen relacionados con el segundo factor de forma negativa y se localizan fundamentalmente en el distrito de Barajas, cercano a la base militar de Torrejón. Los americanos del Sur, en una posición intermedia entre los anteriores, se caracterizan por un nivel académico y profesional medio, y rasgos demográficos de juventud y dependencia. Hortaleza, Ciudad Lineal y Moratalaz son los distritos en los que se ubican predominantemente.

Un segundo bloque lo forman el resto de los inmigrantes, procedentes en su mayoria de países del Tercer Mundo. Tienen puntuaciones negativas respecto al primer factor (bajo nivel de estudios y dificultades para encontrar empleo). Los africanos y centroamericanos son los mejor caracterizados en este factor y se asientan entre el Sur y el Este de la ciudad, en distritos de un bajo nivel social (Usera, San Blas, Villaverde, etc.). Los asiáticos, por su parte, se ocupan fundamentalmente en el pequeño comercio-restauración y los servicios personales, y se localizan en distritos centrales, con un cierto deterioro urbano. 


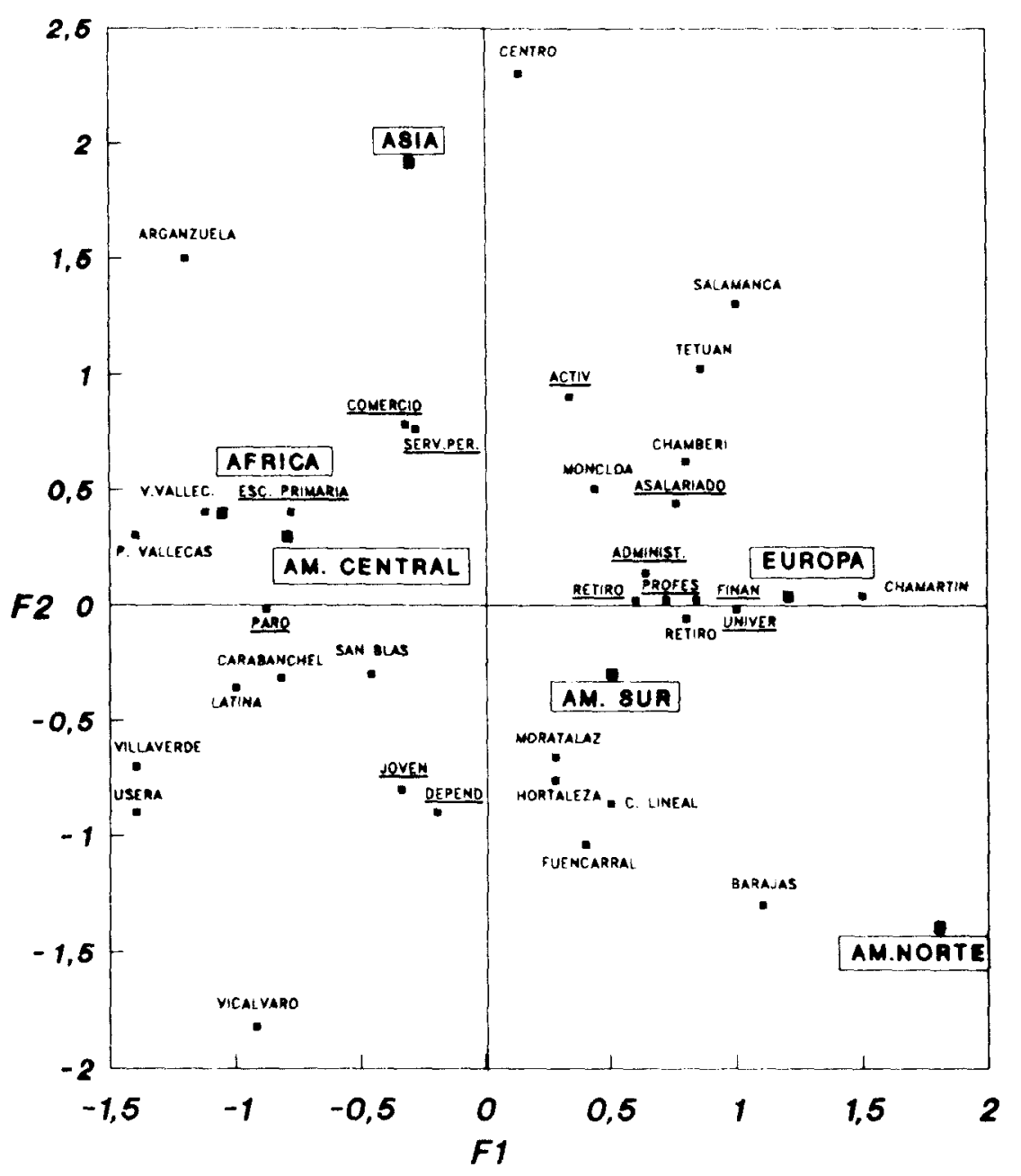

Fig. 5. Distribución de inmigrantes según su origen y características en los dos primeros factores 
En resumen, queda demostrada la existencia de una segregación social y espacial entre los inmigrantes extranjeros que han llegado a Madrid en la década de los años ochenta, que coincide a grandes rasgos, con la que se detecta en el espacio urbano de Madrid.

\section{BIBLIOGRAFIA}

Aguilera, M. J.; G. Yanci, M. P.; Rodriguez, V. (1991): "Los inmigrantes extranjeros en el municipio de Madrid", Actas de las III Jornadas de la Población Española. Málaga, págs. 13-21.

Campo, A. del (1983): «Una aplicación de ecologia factorial al estudio de las pautas espaciales de segregación social en el municipio de Madrid", Ciudad y Territorio n. ${ }^{2}$, págs. 137-153.

Castells, M. (1981): Crisis urbana y cambio social. Madrid, Ed. Siglo XXI.

Colectivo I. O. E. (1987): "Los inmigrantes en España", Revista de Estudios Sociales y de Sociologia Aplicada n. 66 . Madrid, Cáritas Española, 366 páginas.

FOESSA (1967): Informe sociológico sobre la situación social de Madrid. Madrid, Fundación Foessa.

Gozalvez, V. (1990): “El reciente incremento de la población extranjera en España y su incidencia laboral", Investigaciones Geográficas, págs. 7-36.

JIMÉNEZ, B. C. (1984): “Aproximación metodológica al estudio de la diferenciación residencial urbana en Madrid", Anales de Geografia de la Universidad Complutense n. 4 , págs. 167-187.

- (1987): Análisis geográfico y representación geográfica del mosaico social de Madrid. Madrid, Instituto Geográfico Nacional, 229 págs.

LoRa-Tamayo, G. (1990): “Una revisión de los estudios sobre diferenciación sociodemogrática referidos a la ciudad de Madrid", Espacio, Tiempo y Forma, Geografia, serie 6, tomo 3 . págs. 55-92.

Muñoz, F.; Izouierdo, A. (1989): "L'Espagne pays d'immigration", Population, vol. 44, n. 2 , págs. 257-289.

SALCEDO, J. (1977): "Segregación dirigida y pautas de asentamiento en el municipio de Madrid", Revista Internacional de Sociologia, n. 24

SIMÓN, G., (1989): "Los fenómenos migratorios en Europa meridional, panorama general», OCDE. El futuro de las migraciones. Madrid, MTSS, págs. 389-438. 